\title{
Resistance to parasites in lactating rats is sensitive to protein but not energy supply
}

\author{
P. Sakkas ${ }^{1}$, L. Jones ${ }^{1}$, J. G. M. Houdijk ${ }^{1}$, D. P. Knox ${ }^{2}$ and I. Kyriazakis ${ }^{1,3}$ \\ ${ }^{1}$ Animal Health, SAC, Edinburgh EH9 3JG, UK, ${ }^{2}$ Parasitology Division, Moredun Research Institute, Penicuik EH26 OPZ, \\ UK and ${ }^{3}$ Veterinary Faculty, University of Thessaly, 43100 Karditsa, Greece
}

Periparturient relaxation of immunity (PPRI) to parasites in mammals results in increased worm burdens and worm egg excretion and may have a nutritional basis ${ }^{(1)}$. It has indeed been shown that Nippostrongylus brasiliensis re-infected lactating rats fed low-crude protein $(\mathrm{N} \times 6.25 ; \mathrm{CP})$ diets showed an augmented extent of PPRI compared with their high-protein-fed counterparts ${ }^{(2)}$. However, effects of $\mathrm{CP}$ intake were confounded with metabolizable energy (ME) intake as a result of increased food intake on the high-protein diets. Here, effects of CP and ME supply on PPRI were independently assessed.

Second-parity rats were infected with $1600 \mathrm{~N}$. brasiliensis larvae before mating (primary infection). On parturition dams were allocated to one of six feeding treatments (1-6) consisting of two levels of ME supply at one of three levels of CP supply; feeding treatments were balanced for parturition body weight (PBW; $n$ 14). Feeding treatments 1,2 and 3 were calculated to supply $1.05 \mathrm{MJ}$ ME/kg PBW per d, whereas treatments 4,5 and 6 were calculated to supply $1.40 \mathrm{MJ} \mathrm{ME} / \mathrm{kg}$ PBW per d. In addition, CP supply was calculated to incrementally increase from scarce to more than adequate at each level of ME intake: 6.6, 13.3 and $19.9 \mathrm{~g} / \mathrm{kg}$ PBW per d for feeding treatments 1,2 and 3 respectively; 13.3, 19.9 and $26.5 \mathrm{~g} / \mathrm{kg}$ PBW per d for treatments 4,5 and 6 respectively. Rats were re-infected with $1600 \mathrm{~N}$. brasiliensis larvae on day 2 of lactation (secondary infection), when litter size was standardized at ten pups. Dams and litters were weighed daily until either on day 8 or day 11 of lactation when worm burdens (number and gender) were assessed as a proxy for PPRI.

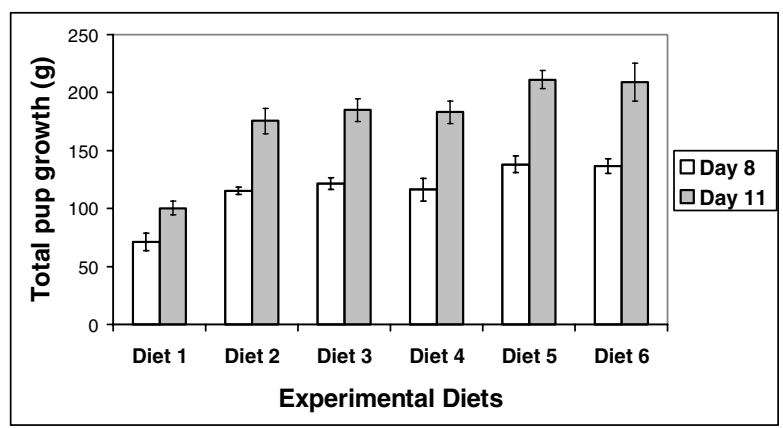

Fig. 1. Pup weight gain

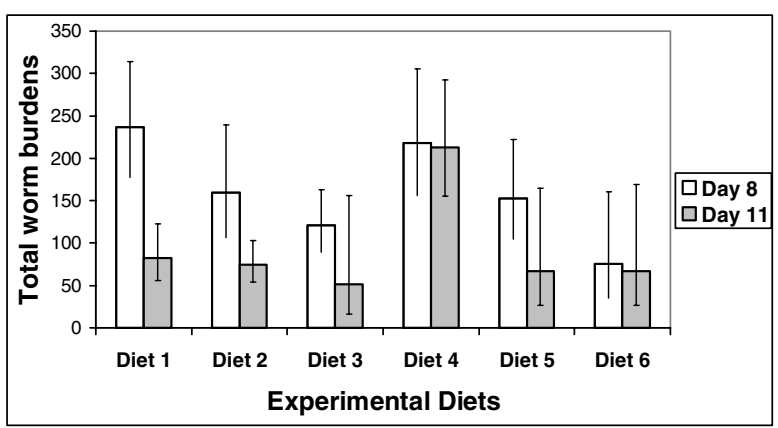

Fig. 2. Worm burdens.

Feeding treatment and time did not interact for any of the variables assessed $(P>0.20)$. Pup weight gain increased (Fig. 1) and dam body-weight loss was reduced (data not shown) with increased energy and protein intake $(P<0.001)$. Energy and protein supply did not interact for dam body-weight loss and for pup weight gain. Energy intake did not affect worm burdens (Fig. 2) and worm burden composition (data not shown). However, increasing protein supply reduced worm burdens $(P<0.01)$ at both levels of energy, whilst increased protein supply reduced the proportion of female worms at the lower level of energy only $(P<0.05$; data not shown).

These results support the view that the periparturient breakdown of immunity to $N$. brasiliensis is sensitive to changes in protein but not energy intake. They also suggest that hosts with higher resistance may expel female worms at a higher rate than male worms. This factor could incur benefits to the host, since female worms are larger and heavier than male worms and may cause more damage to parasitized hosts.

1. Coop RL \& Kyriazakis I (1999) Vet Parasitol 84, 187-204.

2. Jones LA, Houdijk JGM, Knox DP et al. (2009) Parasite Immunol (In the Press). 